
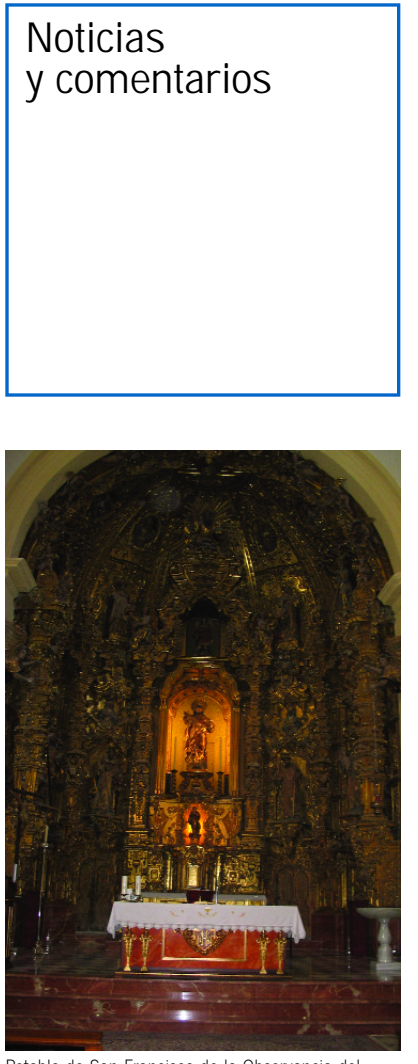

Retablo de San Francisco de la Observancia del Colegio de los Jesuitas del Puerto de Santa Maria. Imagen: R. Lacanal

\title{
La conservación de retablos ha de abordarse desde el diseño de planes especiales interdisciplinares
}

El VIII Encuentro de Primavera del Puerto de Santa María (Cádiz), celebrado durante el pasado mes de abril, se centró en presentar los retablos como piezas patrimoniales complejas que requieren de una atención o un plan especial; que exige la acción interdisciplinaria. Si bien es cierto que se han creado metodologías desde las distintas disciplinas para el conocimiento de los retablos, creemos que no se cuenta en la actualidad con un instrumento capaz de analizar el tema desde el punto de vista de la Conservación.

Cuando se habla de la conservación de los retablos no bastan los puntos de vista particulares, sino que hay que avanzar; hay que crear relaciones entre las distintas disciplinas que tienen campos específicos; hay que generar un mapa sobre la conservación de los retablos o trazar, dada su complejidad, un PLAN ESPECIAL.

La conservación de los retablos debe ser por tanto una labor conjunta y multidisciplinar, sistémica, ya que se logra su objetivo a través de distintas estrategias: el conocimiento y la investigación, la catalogación científica y los inventarios, el diagnóstico y la restauración, la museología y exposición, la difusión y la educación. Este mapa comprende las estrategias para la transmisión de los retablos a las generaciones futuras:

$>$ Conservación de la memoria histórica, a través del conocimiento de documentos en archivos.

> Profundización en investigación sobre retablos. > Creación ampliación de inventarios, catálogos y registros como instrumentos de tutela.

$>$ Mecanismos de protección por la ley.

$>$ Estudios y planes de diagnóstico que permitan conocer mejor su estado de conservación.

> Planes de intervención y restauraciones.
> Planes de mantenimiento, museificación y protección preventiva.

> Respeto a su función de culto y creación de estrategias compatibles para la difusión y educación.

Pero el encuentro puso en evidencia también el mapa de la no conservación. Existen retablos que desaparecen, envejecen, se mutilan y se destruyen. Existen retablos que se abandonan, desaparecen por el fuego, se desmembran o cuyos elementos se cambian de lugar. Existen retablos a los que le faltan piezas porque han sido robadas, que permanecen mal iluminados o sucios, etc. El peligro y los factores de destrucción están presentes y las medidas preventivas vienen a ser aquellas que palian o evitan un posible deterioro, antes de que este se produzca.

Este planteamiento enlaza el conocimiento histórico artístico con la valoración patrimonial y genera un mapa o itinerario que además de conocer la obra de arte, penetra en su fragilidad, en su forma de estar y existir en el tiempo, comprendiendo su existencia, como el resultado de una labor de conservación. La Conservación es una disciplina que analiza el patrimonio en relación al tiempo y aborda su posible o real desaparición y pérdida de valor o, por el contrario, su permanencia como valor.

Deriva del estudio una visión más compleja, pero también más real, rica y efectiva en cuanto a que el retablo como Patrimonio histórico-artístico se transforma del objeto de estudio histórico-estético, en objeto de preocupación social, cuyo objetivo es la transmisión al futuro.

María Dolores Ruiz de Lacanal

Facultad de Bellas Artes

Universidad de Sevilla

\footnotetext{
Abierto el plazo de presentación de trabajos para la edición 2005 de los Premios Europa Nostra

$>$ Convoca: Comisión Europea - Programa Cultura 2000

$>$ Título: Premio de la Unión Europea al Patrimonio Cultural - Premio Europa Nostra

> Objetivo: reconocer y promover la buena gestión en las prácticas de conservación del patrimonio, así como para estimular el intercambio de conocimiento y experiencia en Europa

> Categorías: 1) proyecto en el campo de la conservación, restauración y rehabilitación de Patrimonio Arquitectónico, Paisajes Culturales, Colecciones de Obras de Arte y Sitios Arqueológicos, 2) estudio cuyo fin último sea llevar a efectos tangibles la conservación o realce de cualquiera de las áreas mencionadas en la categoría anterior, 3) servicio dedicado a la conservación del patrimonio por individuos o grupos > Fecha límite de solicitudes: 1 de agosto de 2005 para la categoría 2 y 15 de septiembre de 2005 para las categorías 1 y 3 